\title{
Analyses of Steel Bridge Circular Columns using Fiber Model considering Local Buckling
}

\author{
Kinoshita, K. ${ }^{1}$
}

\begin{abstract}
One of the most concerned problems for analytical estimation of ultimate strength and ductility of steel bridge columns is the consideration of local buckling. Stress-strain curves with softening behavior to include local buckling in fiber model analysis method were proposed by several researchers. However, accuracy of those models is still relatively low. As a consequence, most steel bridge designs have been done using fiber model analysis method without consideration of local buckling. In order to improve the analytical response estimation of steel bridge columns, a fiber model analysis method considering local buckling is proposed in this study. In this method, multi-fiber elements were used to model the local buckling length to simulate local buckling deformation. The proposed method shows good results not only for estimating peak strength but also post-peak strength compared to previous experimental results. However, further research should be directed to improve the accuracy of the deformation modes.
\end{abstract}

Keywords: Fiber model, local buckling, steel bridge circular columns.

\section{Introduction}

Consideration of local buckling on analytical estimation of ultimate strength and ductility of steel bridge columns is one of the important lessons learned from severe bridge damage in past earthquakes (Figure 1). This local buckling was found in many different forms including variations from different column sections.

In general, fiber model analysis is used for seismic evaluation of not only reinforced concrete columns, but also steel bridge columns. The earliest study by Park et al. [1] used the fiber model analysis for a reinforced concrete member. Following this study, the fiber model analysis was used and developed $[2,3]$. A recent study on the seismic performance of a reinforced concrete bridge column tested on the $\mathrm{E}$ Defense, which is a full-size, three-dimensional shake table in Japan, was reported by Kawashima et al. [4]. The study confirmed the accuracy of the fiber model analysis. For steel bridge columns, analytical studies using the fiber model analysis were reported by Watanabe and Sakimoto [5], Tokunaga et al. [6]. Moreover, for steel bridge columns with the consideration of local buckling, there are modeling techniques that include local buckling effects in the stress-strain curves of the plastic hinge zone, where local buckling is occurred.

${ }^{1}$ Assistant Professor, Dept. of Civil Engineering, Gifu University, JAPAN. Email: kinosita@gifu-u.ac.jp

Note: Discussion is expected before June, $1^{\text {st }} 2014$, and will be published in the "Civil Engineering Dimension" volume 16, number 2, September 2014.

Received 17 May 2013; revised 10 June 2013; accepted 14 August 2013.

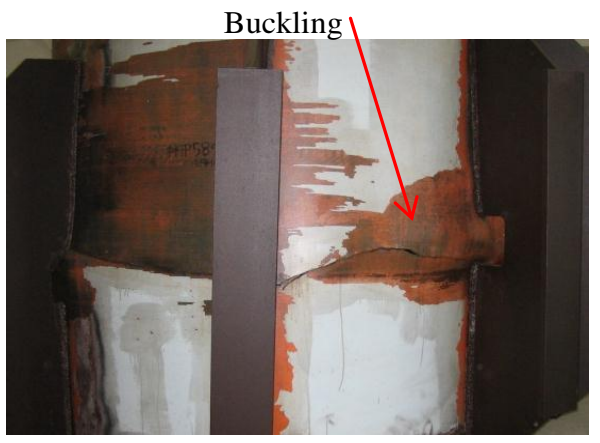

(a) Circular Column

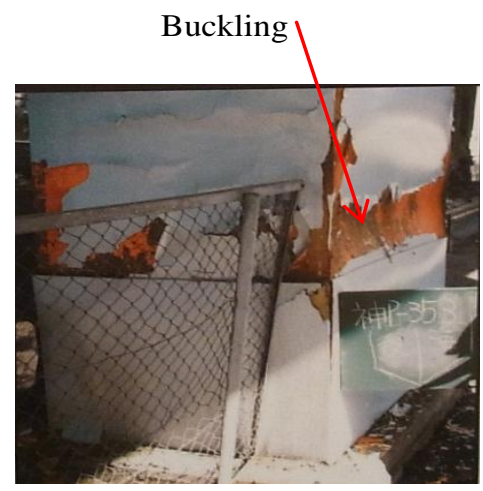

(b) Box Column

Figure 1. Damaged Steel Bridge Column, Kobe Earthquake, 1995

Although the modeling techniques are not new and many suggestions have been made in previous studies [7-8], in practice, a common assumption in the analysis of steel bridge columns using fiber model is to ignore the local buckling. The Japanese Standard Specification for Seismic Design of Steel and Composite Structures [9] permits these 
structures to be evaluated using the average strain of the plastic hinge zone as an alternative to evaluate peak strength without consideration of local buckling. However, Kakiuchi et al. [10] concluded that this approach cannot capture the actual behavior and would result to overly conservative evaluation.

The common assumption may be based on two major reasons. First, some of the suggested models do not have hard evidence that they can capture actual behavior because of lack of agreement with experimental results, and second, there are many different forms of local buckling as mentioned above. It is therefore necessary to develop new modeling techniques that can provide not only a better representation for local buckling, but also have good agreement with the experimental results.

A recent study on a fiber modeling technique to estimate local buckling of longitudinal bars in reinforced concrete (RC) columns was reported by Ichikawa et al. [11]. The study aimed to directly capture non-linear deformation of local buckling by using fiber elements to model longitudinal bars individually. The study shows a possibility of further extension of the fiber modeling technique. However, there has been no further study to develop fiber modeling technique for steel bridge columns.

The main objective of this study is to propose a fiber model analysis method considering local buckling of steel bridge circular columns. In this method, to simulate local buckling deformation, multi-fiber elements are used to model the local buckling length in the plastic hinge zone. This concept is different from previous studies that consider effects of local buckling in the stress-strain curves of the plastic hinge zone. This paper discusses analysis results using the proposed method compared to the previous experimental works.

\section{Overview of Previous Steel Bridge Circular Columns Experiment [12]}

The geometry and section properties of the steel bridge circular column used in the analyses are shown in Figure 2 and summarized in Table 1. This experimental work was carried out by Public Works Research Institute (PWRI) [12]. The column was 900 $\mathrm{mm}$ in diameter with $9 \mathrm{~mm}$ thickness. The boundary conditions were:

a) Fixed column base that was fixed by high tension bolts or pre-stressed steel bars. The base was built-up sections consisting of thick steel plates, and hence was assumed to be rigid.

b) Pin connection between the top of the column and loading jacks of each direction.

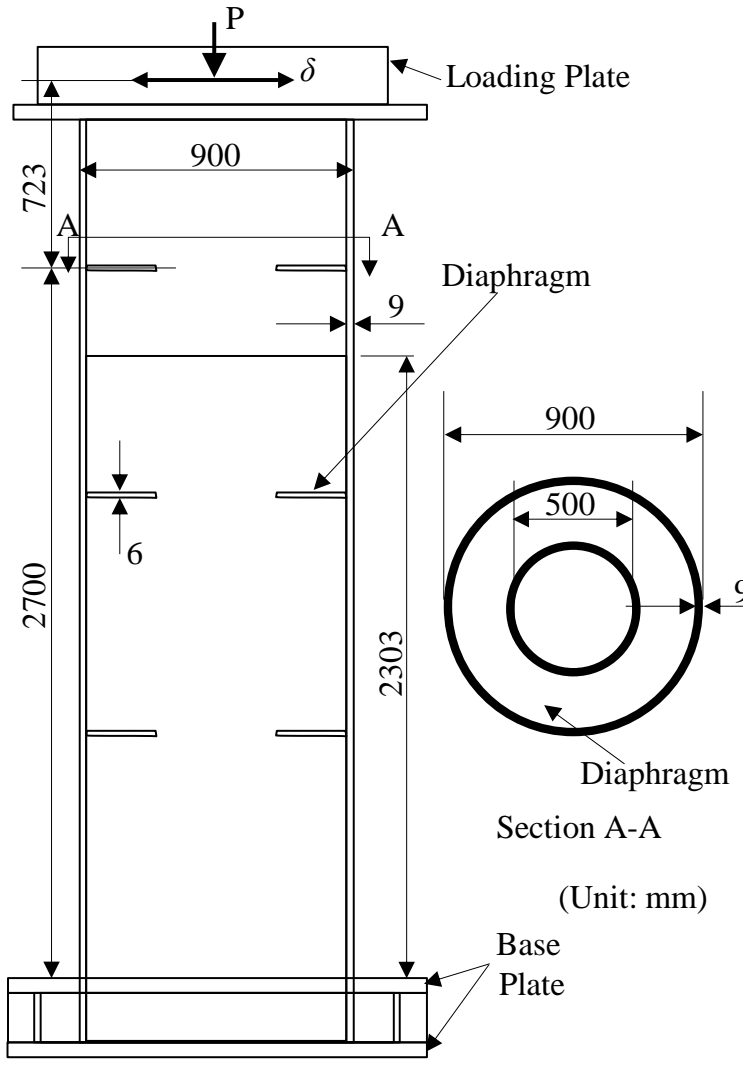

Figure 2. Steel Bridge Circular Column Model [12]

Table 1. Properties of the Column Model

\begin{tabular}{cc}
\hline & Experimental Model \\
\hline Steel Grade & SS400 \\
Height $h(\mathrm{~m})$ & 3.423 \\
Thickness $t(\mathrm{~mm})$ & 9 \\
Diameter $D(\mathrm{~mm})$ & 900 \\
$\bar{\lambda}$ & 0.268 \\
$R_{t}$ & 0.123 \\
$H_{0}(\mathrm{kN})$ & 400.82 \\
$\delta_{y}(\mathrm{~mm})$ & 10.5 \\
$P / \sigma_{y} A$ & 0.199 \\
\hline
\end{tabular}

A displacement-controlled testing on the horizontal direction with an axial load was conducted with the loading history, shown in Figure 3, which was applied to the column. The ratio of the axial force, $P$, to the value of the yield strength of steel plate, $\sigma_{y}$, multiplied by the section area, $A$, was approximately $20 \%$. The slenderness parameter, $\bar{\lambda}$, the radius thickness parameter, $R_{t}$, the yield horizontal strength, $H_{0}$, and the yield horizontal displacement, $\delta_{y}$, in Table 1 are given as follows:

$$
\begin{aligned}
& \bar{\lambda}=\frac{2 \mathrm{~h}}{\pi \sqrt{\mathrm{I} / \mathrm{A}}} \sqrt{\frac{\sigma_{\mathrm{y}}}{\mathrm{E}_{\mathrm{s}}}} \\
& \mathrm{R}_{\mathrm{t}}=\frac{\mathrm{R}}{\mathrm{t}} \frac{\sigma_{\mathrm{y}}}{\mathrm{E}_{\mathrm{s}}} \sqrt{3\left(1-\mathrm{v}_{\mathrm{s}}^{2}\right)}
\end{aligned}
$$




$$
\mathrm{H}_{0}=\left(\sigma_{\mathrm{y}}-\mathrm{P} / \mathrm{A}\right) \mathrm{Z} / \mathrm{h}
$$

$$
\delta_{0}=\mathrm{H}_{0} \mathrm{~h}^{3} / 3 \mathrm{E}_{\mathrm{s}} \mathrm{I}
$$

where $v_{\mathrm{s}}$ is the Poisson's ratio of the steel plate, $\mathrm{E}_{\mathrm{s}}$ is the modulus of elasticity of steel, I is the moment of inertia and $\mathrm{Z}$ is the section modulus. The experiment showed that the peak-strength was about $553 \mathrm{kN}$, and local buckling occurred at the bottom plastic hinge zone of the column, which is known as "elephant foot bulge".

\section{Fiber Modeling of Steel Bridge Circular Columns}

In general, the circular column is modeled as a single fiber element that has fine fiber division in the section (Figure 4). In the circular column, local outof-plane bending deformation is created due to local buckling, however, the local out-of-plane deformation cannot be obtained from single fiber element, because each fiber division calculates only the axial deformation. Because of this, this modeling does not give results for out-of-plane deformation such as local buckling.

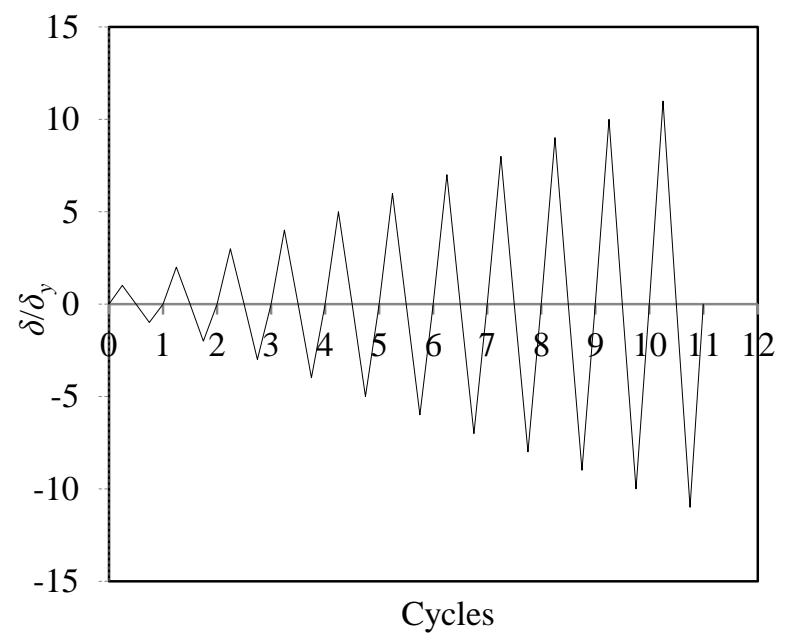

Figure 3. Displacement Controlled Testing Protocol

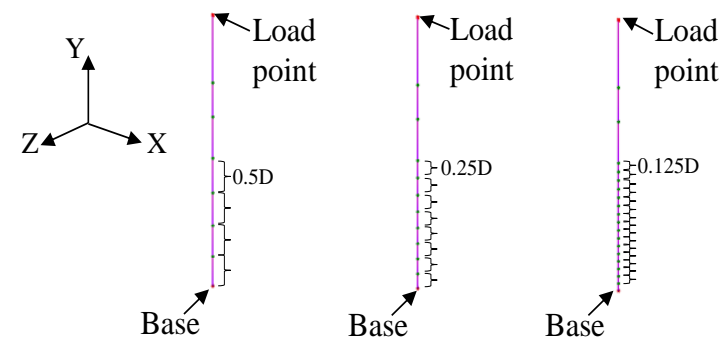
(a) $0.5 \mathrm{D}$
(b) $0.25 \mathrm{D}$
(c) $0.125 \mathrm{D}$

Figure 4. Single Fiber Model

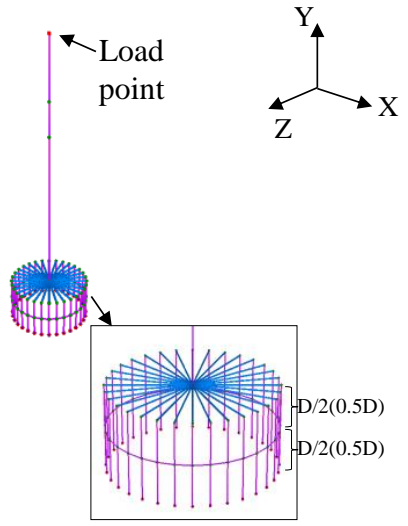

(a) $\mathrm{D} / 2$

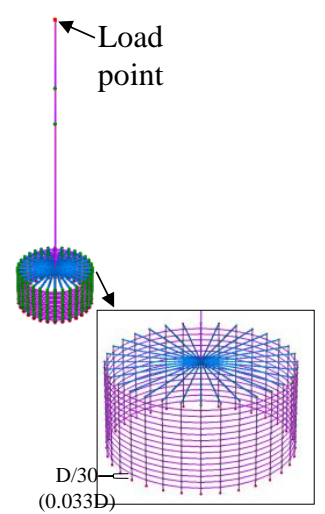

(b) $\mathrm{D} / 30$
Figure 5. Proposed Fiber Model

Previous studies tried to consider softening for postpeak behavior in order to assume local buckling in the stress-strain curve of steel plates. However, as mentioned above, this approach may not be able to capture the actual behavior of every steel bridge column because of lack of agreement with experimental results. Moreover, additional calculations based on experimental tests or finite elements analyses are required to consider more accurate stress-strain curve. In fact, some of calculations are complicated. In the proposed model (Figure 5), the plastic-hinge zone is modeled as multi-fiber elements while the general region is modeled as single fiber elements. This way the out-of-plane bending deformation can be captured directly. Thus, the proposed model takes advantage of the modeling technique that does not need any additional calculations. A bi-linear stress-strain curve with post yield stiffness, which is assumed as 1\% of the Young's Modulus of steel plate, was used to model the steel plates. The yield strength of steel plate, $\sigma_{y}$, is assumed as $308 \mathrm{~N} / \mathrm{mm} 2$, which corresponds to the experimental tests. The effect of element division on the single fiber model (see Figures 4(a), (b), (c)) was investigated.

\section{Effect of Modeling}

\section{Strength}

Different analysis results from the single fiber model case and multi-fiber model cases are presented in terms of strength and deformation. The effect of modeling was determined by comparing with the experimental results as the baseline. In addition, the results are also compared with the previous analysis results by Goto et al. [13] that used finite element model.

Figures 6 to 9 show the relationship between load and displacement at the loading point. Figure 6 
indicates that the effect of element division (see Figures 4(a), (b), (c)) on the single fiber model is not significant. Therefore, the results using $0.5 \mathrm{D}$ element division used for a comparison with the experiment results. As shown in Figure 7, the discrepancy in this relationship is observed. The single fiber model overestimates not only the peak strength, but also post-peak strength. The peak strength obtained from the single fiber model can be about 1.5 times greater than in the peak strength from the experimental results. This is due to the use of the bi-linear stress-strain curve in the steel plates without consideration of local buckling, which stiffens the plastic hinge zone causing it to allow more load to be carried. This overestimation can have a significant effect during seismic performance evaluation.

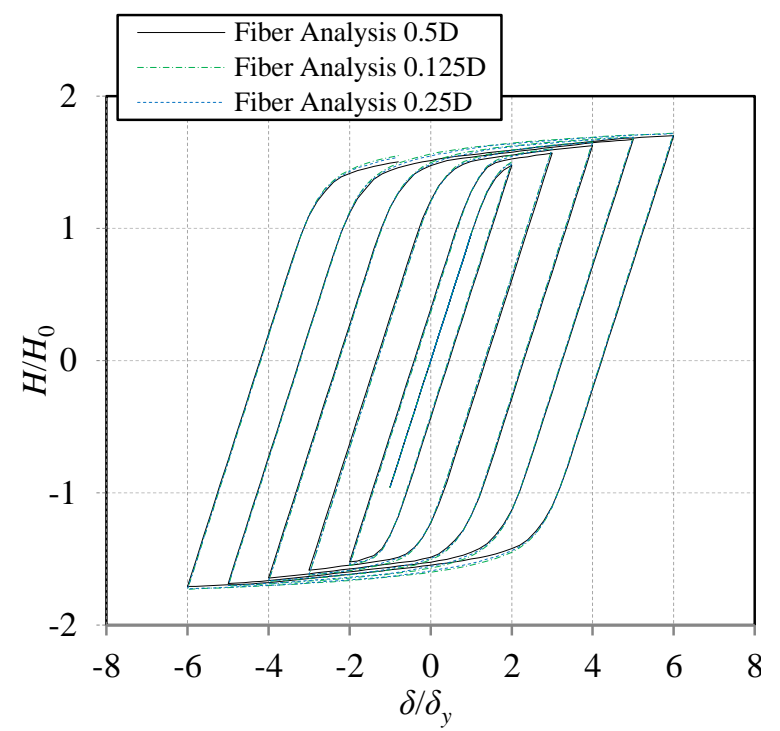

Figure 6. Effect of Element Division on Single Fiber Model

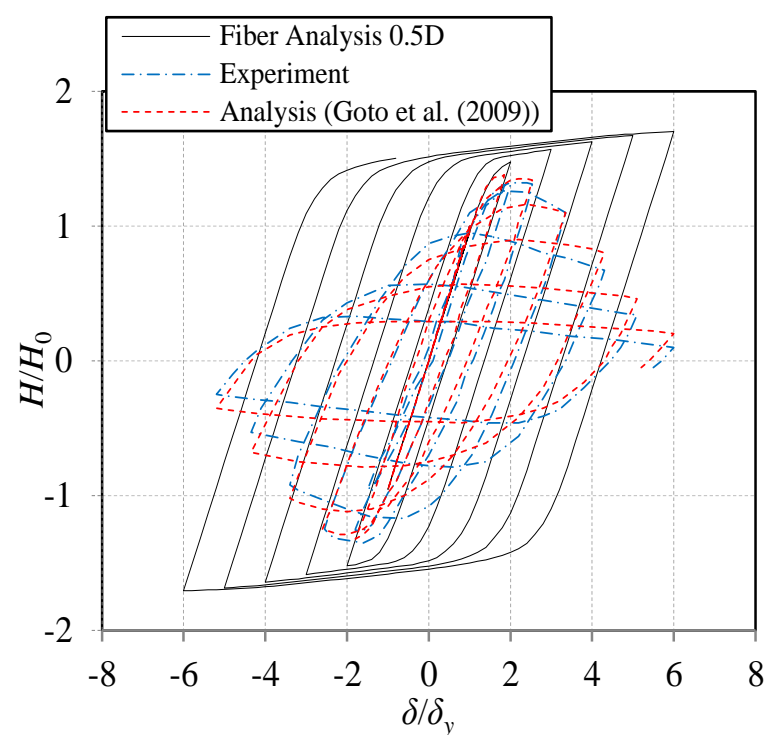

Figure 7. Comparison of Relationship between $\mathrm{H} / \mathrm{H} 0$ and

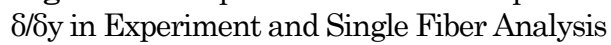

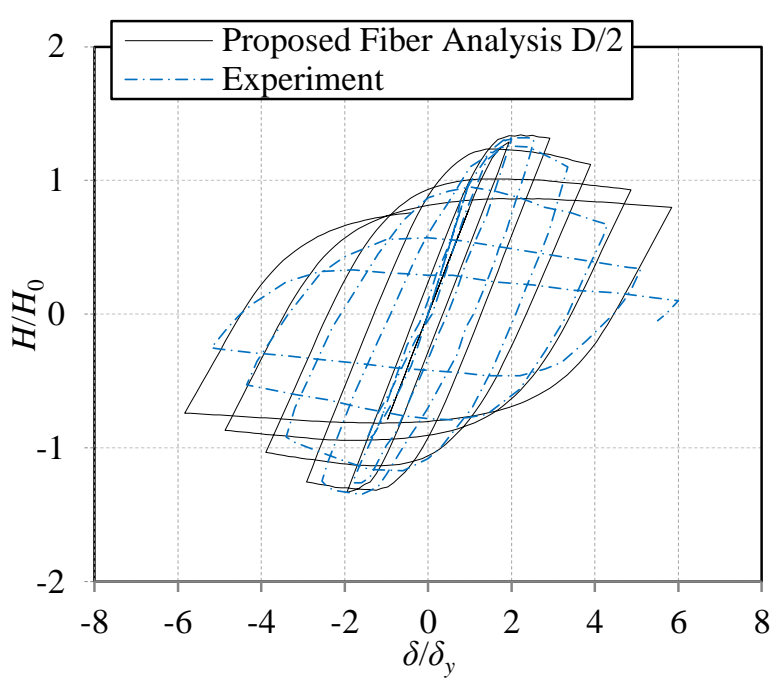

Figure 8. Comparison of Relationship between H/H0 and $\delta / \delta y$ in Experiment and Proposed Fiber Analysis

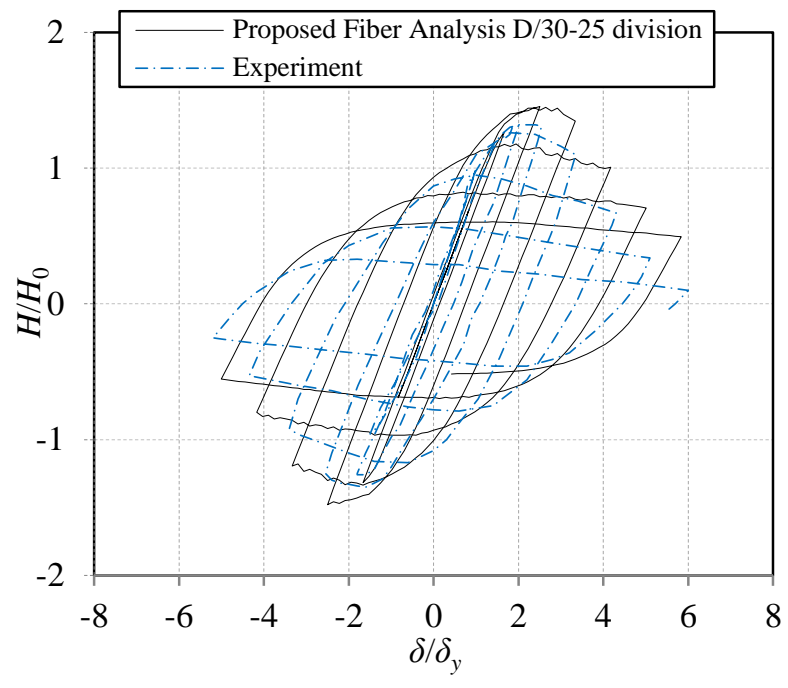

Figure 9. Comparison of Relationship between $\mathrm{H} / \mathrm{H} 0$ and

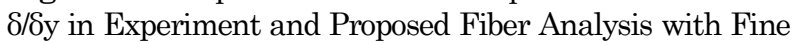
Element Division in the Axial Direction

On the other hand, as shown in Figure 8, the proposed multi-fiber model estimates well the peak strength, and slightly overestimates the post-peak strength, but agrees well with the experimental results compared to the single fiber model. A slight overestimation of the post-peak strength is due to the use of rough fiber element division on the plastic hinge zone. As a follow up, a parametric study has been conducted to study the sensitivity of the division of the fiber elements used on the plastic hinge zone to the results. More specifically, the division of the fiber elements in the axial direction is investigated as shown in Figures 5(a), (b). The division in the circumferential direction is kept the same while the division in the axial direction is varied. Goto et al. [13] also reported that the FEM analysis using shell elements is excellent in 
estimating the response of steel bridge frame piers with the circular columns subjected to cyclic loading when a small element division or fine mesh is utilized. Yamaguchi et al. [14] indicated that the element division on the plastic hinge zone in the axial direction should be less than $\mathrm{D} / 30$ and the aspect ratio of the shell element length in the axial direction to the circumferential direction should be less than $1 / 3$ to accurately capture the peak strength when an error of less than $10 \%$ is desired. In this study the element division of the plastic hinge zone in the axial direction is under $\mathrm{D} / 30$, and the aspect ratio of the length in the axial direction to the circumferential direction in the plastic hinge zone is less than 1/3 (Figure 5(b)). Figure 9 shows that as the element division in the axial direction increases, the post-peak strength decreases and becomes closer to the experiment, but not for the entire history. Therefore, an additional analysis is performed to determine the effect of division of fiber section on the post-peak strength. The division of fiber section was varied from 4-, 9-, 25-, to 100-division as shown in Figure 10. Figure 11 show, that as the division of fiber section in the axial direction decreases, the accuracy of the estimated response in terms of peak strength and post-peak strength improves. More specifically, peak strength of 4-, 9-, 25- and 100division is $1.32,1.42,1.48$ and 1.46 , respectively, and therefore peak strength with fine division agrees well with the experiment results, which is about 1.3.

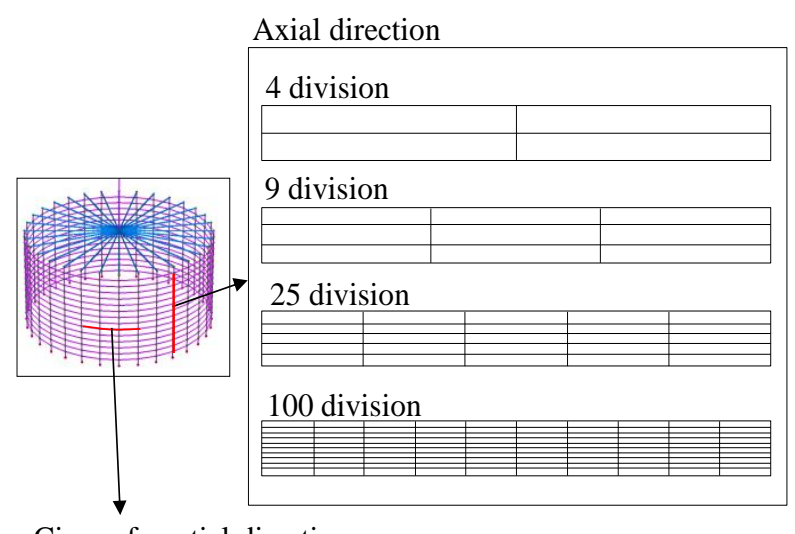

Circumferential direction

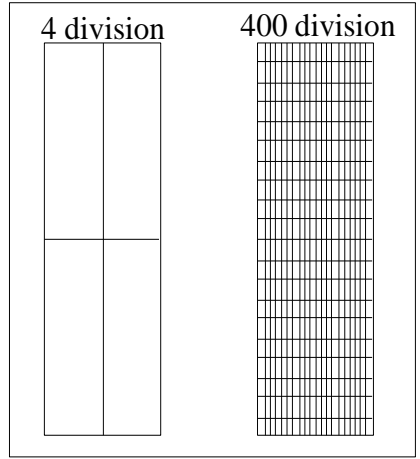

Figure 10. Division of Fiber Section in both the Axial Direction and the Circumferential Direction
Thus, it can be concluded that the division of fiber section in the axial direction has significant effect on the peak strength and post-peak strength. Similarly, the division of the fiber section in the circumferential direction is investigated. As shown in Figure 12, both the peak strength and post-peak strength are similar regardless of the division of the fiber section in the circumferential direction. Therefore, it can be argued that the proposed method, with adequate division of both fiber element and fiber section in the axial direction, gives good results in estimating not only the peak strength, but also the post peak strength.

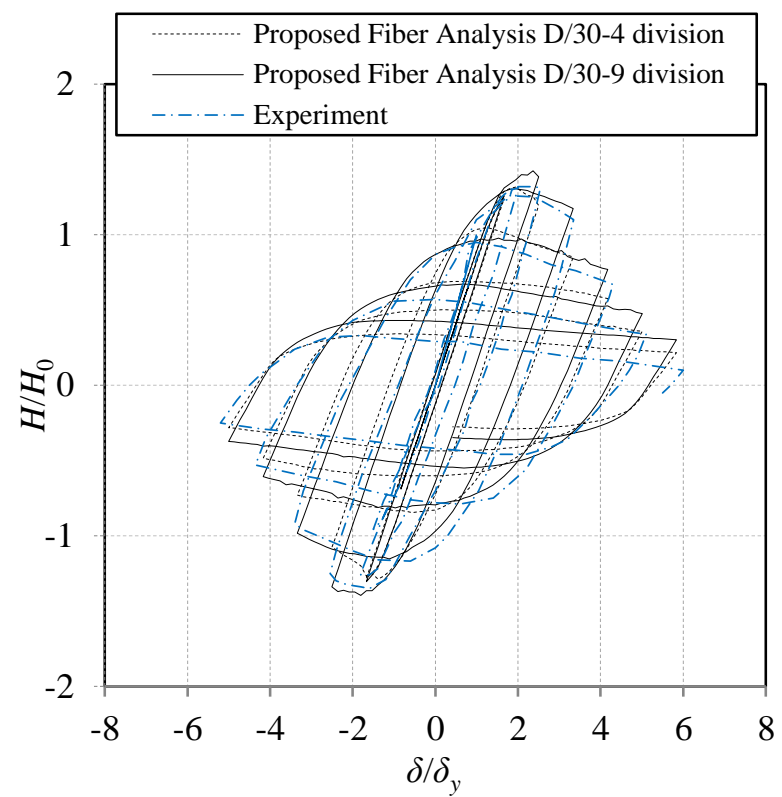

(a) 4- and 9-Division

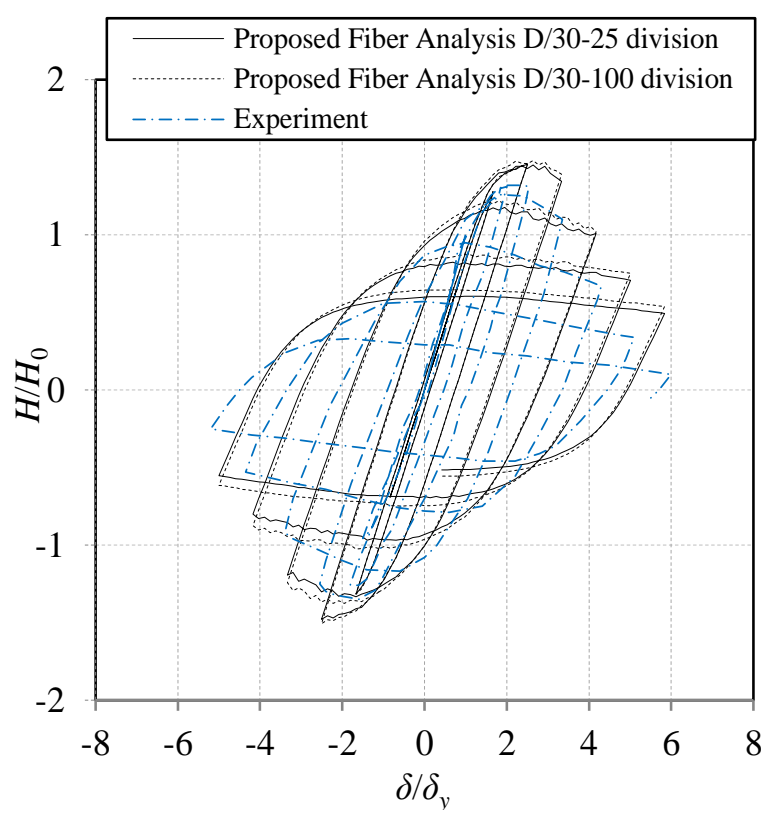

(b) 25- and 100-Division

Figure 11. Effect of Division of the Fiber Section in the Axial Direction 


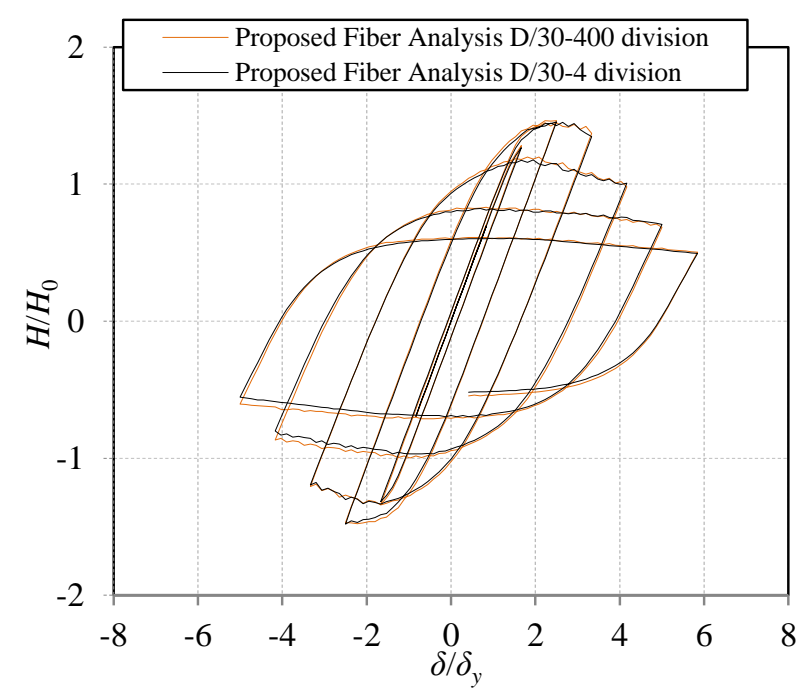

Figure 12. Effect of Division of the Fiber Section in the Circumferential Direction

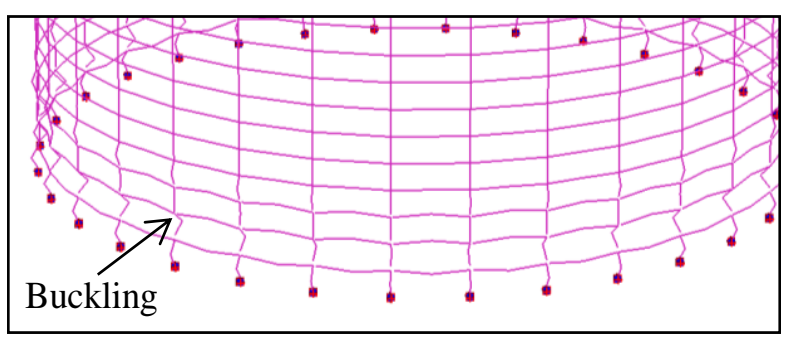

Figure 13. Deformation at Plastic Hinge Zone

\section{Out-of-Plane Bending Deformation}

Figure 13 shows the out-of-plane bending deformation of the plastic hinge zone obtained from the proposed method. As shown, out-of-plane bending deformation due to local bucking occurs in the proposed model. The multi-fiber elements in the plastic hinge zone allow this deformation mode. However, it is also observed that there is a difference in the deformation mode at the plastic hinge zone if compared to the experiment. The proposed model tends to deform toward the inside of the column as opposed to the real deformation observed in experiment. This suggests that some improvements should be made to the modeling of the plastic hinge zone, although estimations of the peak strength and the post-peak strength are good as described as mentioned above.

\section{Conclusions}

Fiber model analysis techniques used in the analysis of steel bridge circular columns have been discussed in this paper. The effect of modeling on strength was determined by comparing results from single fiber model with multi-fiber model proposed in this study. It is shown that peak strength and postpeak strength of the proposed model are comparable to those of the previous experimental work.
However, single fiber model is shown to be prone of large error.

The effect of proposed modeling on out-of-plane bending deformation is determined by comparing the deformation from analysis results using the proposed model to the previous experimental results. It is shown that proposed model can be improved to better capture the out-of-plane bending deformation in the plastic hinge zone, where the local buckling occurred.

\section{References}

1. Park, R., Kent, D.C., and Nielsen, N.N., Reinforced Concrete Member with Cyclic Loading, Journal of the Structural Division, American Society of Civil Engineers, 98(7), 1972, pp. 1341-1360.

2. Sakai, J. and Kawashima, K., Nonlinear Seismic Response Analysis of a Reinforced Concrete Bridge Column by the Fiber Element, Journal of Structural Engineering, Japan Society of Civil Engineers, 55A, 2009, pp. 564572. (In Japanese)

3. Sakai, J. and Unjoh, S., Earthquake Simulation Test of Circular Reinforced Concrete Bridge Column under Multidirectional Seismic Excitation, Earthquake Engineering and Engineering Vibration, 5(1), 2006, pp. 103-110.

4. Kawashima, K., Sasaki, T., Kajiwara, K., Ukon, H., Unjoh, S., Sakai, J., Takahashi, Y., Kosa, K., and Yabe, M., Seismic Performance of a Flexural Failure Type Reinforced Concrete Bridge Column based on E-Defense Excitation, Doboku Gakkai Ronbunshuu A, Japan Society of Civil Engineers, 65(2), 2009, pp. 267-285.

5. Watanabe, H. and Sakimoto, T., Seismic Response Analysis of Concrete-Filled Steel Box Piers considered on Local Buckling, Journal of Structural Mechanics and Earthquake Engineering, Japan Society of Civil Engineers, 647/I51, 2000, pp. 357-368. (In Japanese)

6. Tokunaga, M., Ono, K., Hashimoto, A., Nishimura, N., and Taniue, H., Seismic Evaluation Methods for Steel Members with Fiber Model in consideration of Hysteresis, Doboku Gakkai Ronbunshuu A, Japan Society of Civil Engineers, 65(4), 2009 pp. 898-914. (In Japanese)

7. Ishizawa, T., and Iura, M., Analysis of Tubular Steel Bridge Piers, Earthquake Engineering and Structural Dynamics, 34, 2005, pp. 9851004.

8. Kodama, N., and Yoda, T., Dynamic Response Analysis of Box Section Steel Frames considering Local Buckling, Journal of Structural Mechanics and Earthquake Engineering, Japan Society of Civil Engineers, 731/I-63, 2003, pp. 169-184. (In Japanese) 
9. Japan Society of Civil Engineers (JSCE), The Japanese Standard Specification for Seismic Design of Steel and Composite structures, JSCE, 2008. (In Japanese)

10. Kakiuchi, T., Kasai, A., Inagaki, S., Fujiwara, Y., and Usami, T., Seismic Performance Evaluation of Steel Continuous Bridges with Rigid Superstructure-Pier Connections, Journal of Structural Engineering, Japan Society of Civil Engineers, 55A, 2009, pp. 564-572. (In Japanese)

11. Ichikawa, S., Sasaki, T., and Kawashima, K., Analytical Idealization of Local Buckling of Longitudinal Bars for Analyzing the Seismic Performance of RC Columns, Proc. 13 th Japan Earthquake Engineering Symposium, Japan Association for Earthquake Engineering, 13, 2010, pp. 3247-3254.
12. Public Works Research Institute (PWRI), Summary of the Cooperation Research on the Seismic Limit State Design of Highway Bridge Piers, 1999. (In Japanese)

13. Goto, Y., Kumar, P.G., and Kawanishi, N., FEM Analysis for Hysteretic Behavior of CFT Bridge Piers considering Interaction between Steel Tube and Infilled Concrete, Doboku Gakkai Ronbunshuu A, Japan Society of Civil Engineers, 65(2), 2009 pp. 564-572. (In Japanese)

14. Yamaguchi, E., Oniki, K., Nagamatsu, H., and Nannno, Y., On Finite Element Mesh in Nonlinear Analysis of a Steel Circular-Section Bridge Pier, Journal of Structural Engineering, Japan Society of Civil Engineers, 51A, 2005, pp. 1781-1787. (In Japanese). 